\title{
Cuando los abrazos no sean extraños
}

José Ramón Puerto Álvarez Vicedecano del COAA

\section{RESUMEN}

El texto sirvió como prólogo del catálogo de la exposición "El Arte construye", comisariada por el profesor de la Escuela de Arte de Oviedo, Santiago Martínez, y que estuvo abierta en la sede de Oviedo del Colegio Oficial de Arquitectos de Asturias entre el 3 de octubre de 2020 y el 31 de enero de 2021. Se leyó el día de la inauguración de la muestra como uno de los actos englobados dentro de las actividades culturales de la Noche Blanca de Oviedo.

\section{When hugs stop being strangers}

\section{ABSTRACT}

Text used as prologue of the catalogue of "Art builds" exposition, curated by Oviedo's Art School Professor, Santiago Martínez, and that was open to the public in Oviedo's headquarters of the Official College of Architecture of Asturias between the 3rd of October of 2020 and the 31st of January of 2021. It was read on inauguration day as one of the acts enclosed in the cultural activities of the White Night in Oviedo

\section{PALABRAS CLAVE}

Arte construye, COAA, Asturias, Pandemia

\section{KEYWORDS}

Art builds, COAA, Asturias, Pandemic 
Nuestras vidas, especialmente aquellas que se desarrollan en las grandes ciudades, suelen estar presididas por una vorágine de acontecimientos para las que nos falta tiempo. Ante esa forma de vida parece oportuno recordar aquí una cita marxista (de Groucho), que decía: "Paren el mundo..., que yo me bajo". La expresión del genial cómico americano no dejaba de ser una más de sus ironías punzantes que tan bien supo usar y una situación que se encontraba muy lejos de poder hacerse realidad. 0 así fue hasta el pasado mes de marzo donde el mundo, literalmente se paró.

Durante meses tuvimos que permanecer en nuestros hogares y, quienes lo pudieron hacer, comenzar a trabajar de una manera telemática. Jamás habríamos soñado que una situación así se pudiera producir, pero pasó. Lo imposible se hizo real.

Y hubo tiempo que antes no teníamos, algo que para algunos les complicó la vida al no saber qué hacer con él. A otros, sin embargo, el hecho de no tener que responder a las urgencias del día a día les sirvió de momento de reflexión y surgieron preguntas, muchos interrogantes, que no siempre tuvieron respuesta. Se cuestionaron si lo que estaban haciendo era lo correcto, si era lo que, realmente, querían hacer, si esa manera de estar en el mundo les convencía..., se produjeron crisis personales que permitieron replantear situaciones, anhelos, encauzar, al menos temporalmente, las vidas en otras direcciones. Hubo que volver a construirse 0 , si se prefiere, a reconstruirse, y algunos lo hicieron desde lo que les es próximo y sienten, desde el arte.

A diferencia de lo vivido en pasados siglos varias generaciones hemos tenido la suerte de no haber vivido un conflicto bélico, al menos no de forma cercana. En esos momentos desgarradores los creadores respondieron con las herramientas que tenían y su buen hacer. Los horrores de la guerra fueron para Francisco de Goya inspiración y válvula de escape frente a trabajos que le aportaban seguridad económica, pero, posiblemente, no tantas satisfacciones personales como habría deseado. De la misma forma Pablo Picasso creo una de sus obras maestras haciendo un mural en el que la ausencia de color acentuaba el dramatismo de un homenaje que el pintor malagueño realizó para mostrar al mundo el horror del bombardeo de Guernica, obra que se mostró en 1937 en el Pabellón de los arquitectos Josep Lluis Sert y Luis
Lacasa que en 1937 el gobierno de la República Española construyó para la Exposición Internacional de París.

En los medios de comunicación se apunta que esta extraña situación que ha provocado la pandemia médica sería el equivalente a esos periodos bélicos que vivieron nuestros padres o abuelos, con la diferencia de que en éste hay bajas físicas, pero no materiales. Los cimientos de la sociedad se han movido y nada va a ser igual. Los creadores han sabido también dar respuesta a este momento que estamos viviendo, desde sus casas y en sus estudios reflexionaron sobre ese día a día para plasmar en sus obras los sentimientos y las sensaciones que este extraño periodo les ha dejado. Lo que vendrá después el tiempo lo dirá, pero como hombres y mujeres comprometidos con su tiempo han querido dejar constancia de una realidad a través de sus miradas, y han usado el arte como el poderoso instrumento de transformación que puede llegar a ser, para señalar su forma de estar en el mundo, una manera de expresarse y autoafirmarse frente al colectivo.

Si algo hemos aprendido de estos meses es la fuerza de comunicación que lo virtual ofrece: actividades que realizábamos de manera presencial han pasado a realizarse a distancia, así el trabajo, la formación o el ocio, se han resuelto de forma telemática. Esperando el momento en el que se pudiera volver a visitar un museo o una galería de arte durante el confinamiento desde el COAA consideramos oportuno usar lo virtual como vehículo de difusión para mostrar distintas miradas de quienes tenían algo que contar y nos unimos a la idea que el profesor Santiago Martínez nos presentó. Intentamos que el arte fuera uno de los materiales sobre el que se pudiera construir ese futuro que está por llegar y contamos para ello con una selección de artistas, entre los que se encontraban varios arquitectos del COAA, que diariamente mostraron a través de las redes sociales colegiales en formato vídeo una pequeña pincelada de lo que era su trabajo.

Y si lo digital nos abre nuevas vías no queríamos cerrar otros caminos que ya han sido transitados y nos atrevemos a participar en la publicación de un libro en papel, porque seguimos reconociendo en la materia de sus hojas algo que sigue siendo un excepcional soporte para transmitir y mostrar entre sus páginas imágenes de obras y autores que han colaborado en que este periodo fuera más llevadero. Dentro de 
un tiempo estos meses no serán más que un mal recuerdo y volveremos a abrirlo para encontrar guiños entre obras muy distintas formalmente, propuestas que mantienen su frescor, nuevas miradas sobre algo que no había llamado nuestra atención. Y así será cada vez que pase un poco de tiempo y volvamos a este libro.

Este texto es uno de los prólogos que presentan la publicación realizada y finalizaba diciendo: "Cuando los abrazos no sean extraños y podamos volver a reunirnos será un buen momento para hacer una selección de estas obras que ahora vemos en esta publicación y esperamos poder contemplarlas en una exposi-

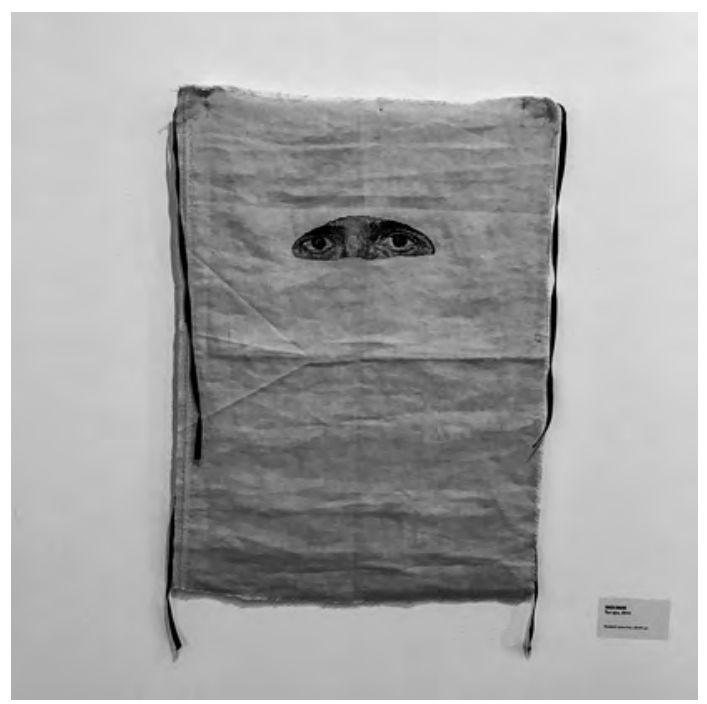

Tus ojos, 2014, María Gimeno. Bordado sobre lino, 60 x $40 \mathrm{~cm}$
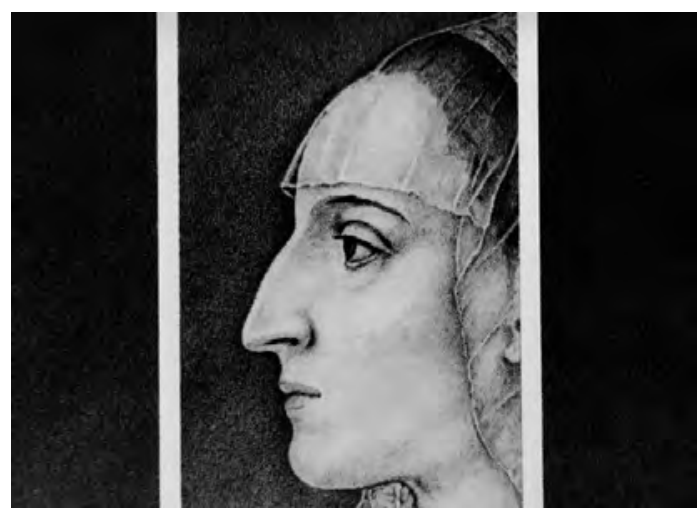

Señaldá 3, 2020, hugo o'donell, lápiz sobre papel, 30 x $50 \mathrm{~cm}$. Cortesía galería gema llamazares, gijón ción a realizar en nuestra sede de 0viedo donde podremos ver, una vez más, que "el arte construye".

Pues bien, ese día ha llegado, los abrazos siguen siendo extraños, pero hemos dado el paso y a pesar de los aforos reducidos sentíamos la necesidad de poder ver físicamente las obras de los artistas que forman el libro. Sabemos que hoy va a ser una Noche Blanca extraña también, pocas personas podrán hoy acercarse a contemplar estas interesantes obras, pero para compensarlo prolongaremos la exposición varios meses para que todo aquel que quiera pueda acercarse y contemplarla.

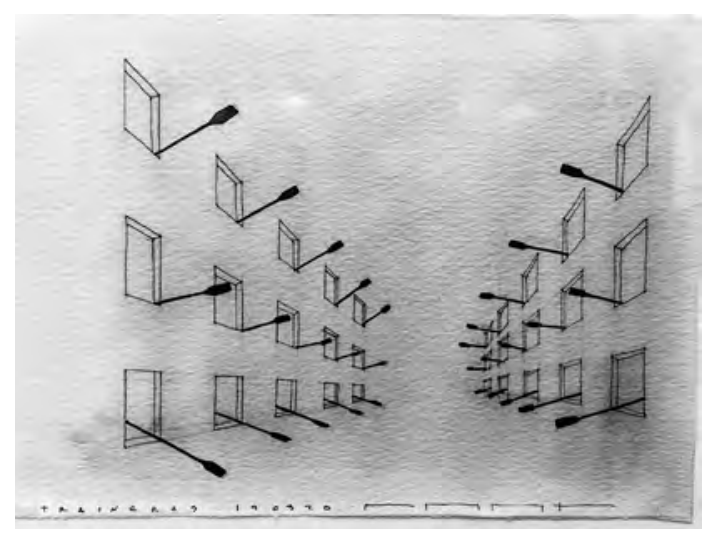

Traineras 190320, 2020, Rodrigo de Miguel. Tinta sobre papel, 25 $\mathrm{x} 17 \mathrm{~cm}$

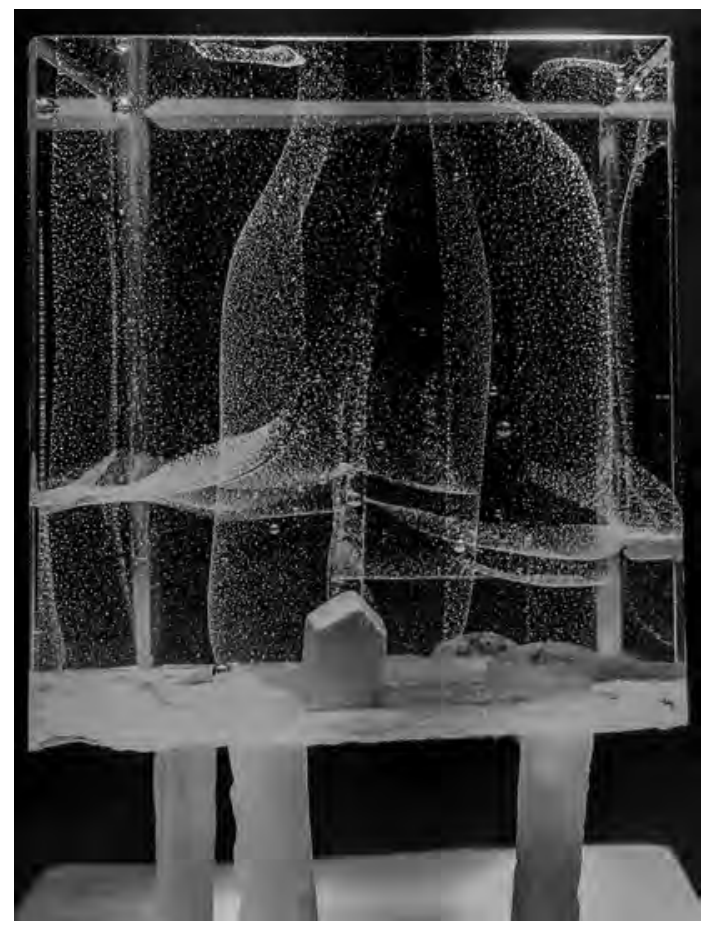

Sin Título, serie Historias sumergidas, 2018, Luis Parades. Vidrio, técnica casting y acabado en frío. $30 \times 30 \times 30 \mathrm{~cm}$ 


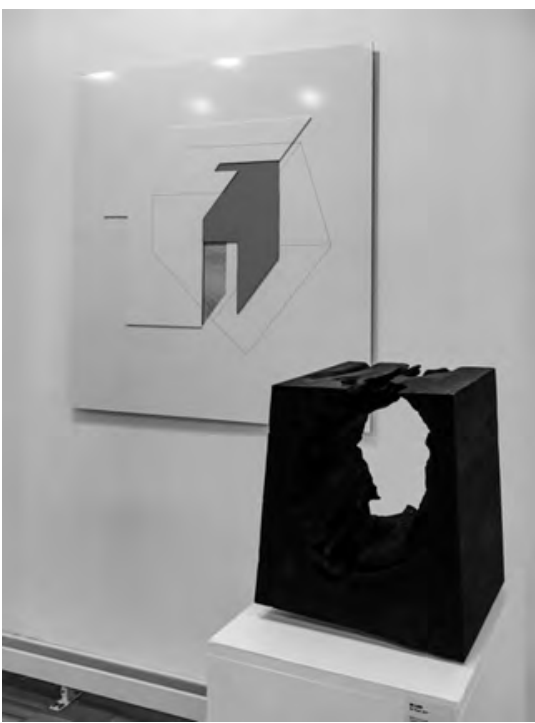

Izda: Sin título, 2020, María Braña. Impresión digital y relieve sobre dibond, 120 × $120 \mathrm{cmDcha}$ : Sin título, 2019, Abe Alonso. Madera de castaño quemada y aceite de linaza, $35 \times 22 \times 35 \mathrm{~cm}$

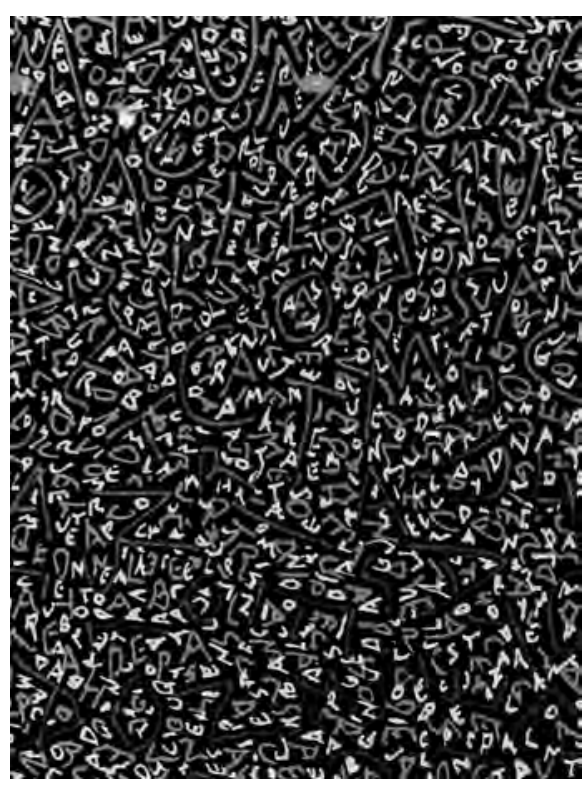

Sin título (detalle), 2020, Gonzalo Tena. Rotulador sobre cartulina, $29 \times 21 \mathrm{~cm}$

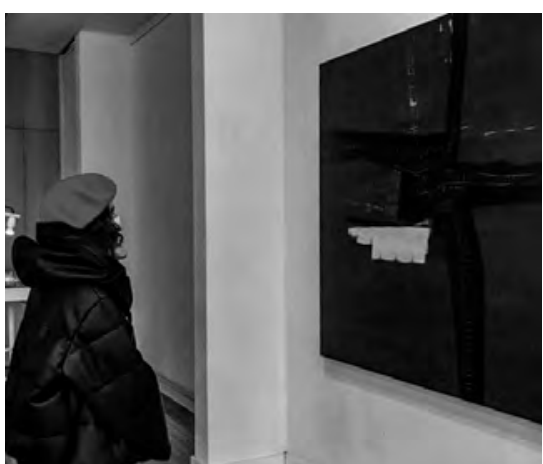

Espectadora viendo la obra Pintura 1, 2015, de Jovino Martinez Sierra. Acrílico sobre tela, 150 x $150 \mathrm{~cm}$

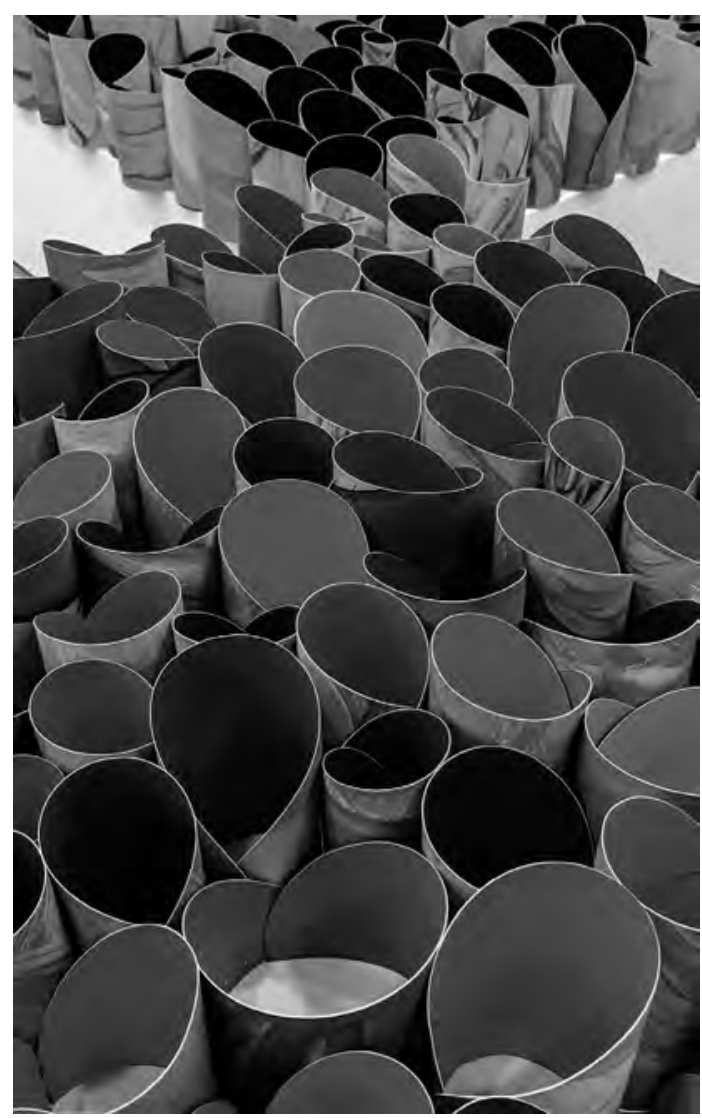

Detalle de "La parte mínima del todo", 2018, Carmen González. Instalación pictórica (detalle), técnica mixta sobre papel, medidas variables

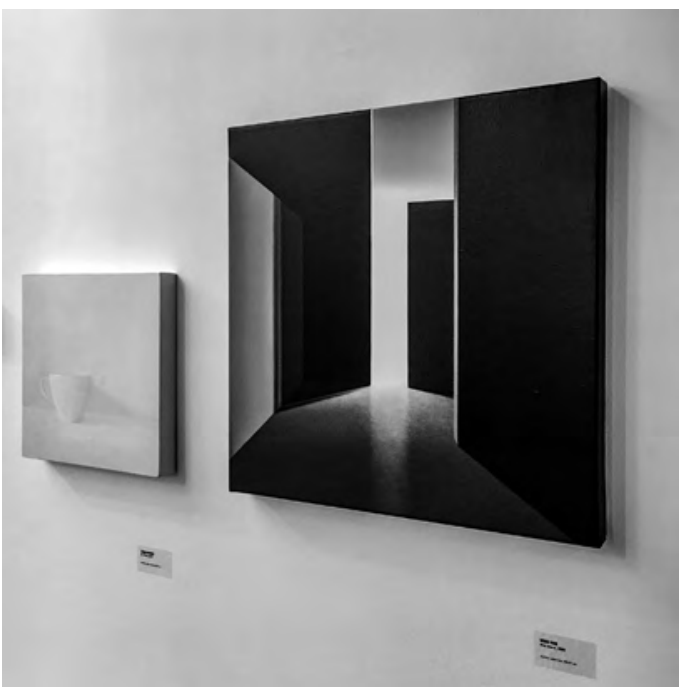

Izda: Sin título, 2017, Jezabel Rodríguez. Acrílico sobre tabla, $30 \mathrm{x}$ $30 \mathrm{~cm}$ Dcha: Out there, 2020, Mónica Dixon. Acrílico sobre lino, $50 \times 50 \mathrm{~cm}$ 